\title{
World Journal of Feasibility of one-shot dilation access in the pediatric age group
}

\author{
Alok Srivastava, ${ }^{1}$ Krishna Kumar Yadav, ${ }^{2}$ Anjana Singh, ${ }^{3}$ Anoop Kumar Srivastava, ${ }^{4}$ \\ Sanjeet Kumar Singh ${ }^{1}$
}

To cite: Srivastava A, Yadav KK, Singh A, et al. Feasibility of one-shot dilation access in the pediatric age group. World $\mathrm{Jnl}$ Ped Surgery 2022:5:e000311. doi:10.1136/wjps-2021-000311

Received 21 May 2021

Accepted 22 November 2021

Check for updates

(C) Author(s) (or their employer(s)) 2022. Re-use permitted under CC BY-NC. No commercial re-use. See rights and permissions. Published by BMJ.

${ }^{1}$ Urology, Dr Ram Manohar Lohia Institute of Medical Sciences, Lucknow, India

${ }^{2}$ Pediatrics, Dr Ram Manohar Lohia Institute of Medical Sciences, Lucknow, Uttar Pradesh, India

${ }^{3}$ Department of Pathology, Mayo Institute of Medical Sciences, Barabanki, Uttar Pradesh, India ${ }^{4}$ Radiotherapy, Dr Ram Manohar Lohia Institute of Medical Sciences, Lucknow, India

Correspondence to Dr Sanjeet Kumar Singh; sanjeetsingh1982@yahoo.in

\section{ABSTRACT}

Objective To compare sequential fascial dilation (SFD) versus one-shot dilation (OSD) in the pediatric patients undergoing percutaneous nephrolithotomy.

Methods The present study is an observational study. The study subjects were divided into two groups. In group 1 , renal dilation was done using the SFD and in group 2, renal dilation was done using the OSD. The amount of time exposed to radiation during access to pelvicalyceal system was estimated. Complications, stone free rates, ancillary procedures for residual stones and hospital stay were compared. Modified Clavien-Dindo classification was used for grading the complications.

Results Radiation exposure and operative time were less in OSD group (95\% confidence interval $(\mathrm{Cl}) 3.068$ to 14.072 , and 2.565 to $12.435, p<0.005)$. The mean drop of hematocrit was statistically less significant in OSD group $(p=0.032)$. In both groups, complications, stone free rate and hospital stay were statistically insignificant.

Conclusions OSD is feasible in the children with reduced radiation exposure and shorter operative time. The outcome was similar to SFD.

\section{INTRODUCTION}

The treatment of choice for treating all forms of kidney stones in adults is percutaneous nephrolithotomy (PCNL). ${ }^{12}$ Woodside et al published the first pediatric series evaluating the use of PCNL in $1985 .{ }^{3}$ PCNL was previously reserved as a secondary technique in children who had failed extracorporeal shock wave lithotripsy (ESWL) or as part of sandwich therapy with ESWL after it was accepted as a safe and effective therapy in children. ${ }^{4}$

Tract creation, dilation and fluoroscopy are the fundamental steps of PCNL. There are primarily four techniques for dilation. These are fascial Amplatz dilator, telescopic Alken type dilator, balloon dilator and 'oneshot dilation' (OSD) techniques. In OSD, the tract was dilated directly by using a $26 \mathrm{~F}$ or 28 F Amplatz dilator. ${ }^{5}$ The amount of radiation a patient is exposed during PCNL is determined by access time, case complexity, and the number of tracts. Because children are three to five times more prone to have radiationinduced morbidity and mortality, it is essential to reduce radiation exposure. Nowadays,
Key messages

What is already known about this subject?

- There are two methods of dilation in percutaneous nephrolithotomy (PCNL), namely one-shot dilation (OSD) and sequential fascial dilation (SFD), which are comparable in terms of results and complications in adults.

- Children are three to five times more prone to have radiation-induced morbidity and mortality.

- There are fewer studies of pediatric age groups on OSD.

What are the new findings?

- OSD is feasible, safe, and well tolerated in the pediatric population.

- OSD had reduced radiation and shorter operative time in comparison with SFD.

- The drop of hematocrit was less in OSD in comparison with SFD.

\section{How might it impact on clinical practice in the} foreseeable future?

- If repeated studies suggest the same findings, it would be better to adopt OSD as the procedure of choice for dilation during PCNL in children with shorter duration of the surgery along with less exposure of the radiation to the children as well as the operative team.

balloon dilation and OSD are considered as the methods of choice to reduce radiation exposure during renal access in the adults. Therefore, a procedure that is either more effective or equally effective but with low radiation exposure is needed, especially in the pediatric population.

In this study, we compared the safety and efficacy of OSD with the sequential fascial dilation (SFD) in PCNL among pediatric patients for operative and radiation exposure time, along with preventing a dilator exchange that could result in increased blood loss.

\section{METHODS}

This is a prospective, observational study done from July 2015 to June 2020 at Dr RML Institute of Medical Sciences, Lucknow, a tertiary 
care teaching hospital. We planned to study the duration of radiation exposure in two surgical steps during PCNL, namely OSD and SFD. We decided to conduct a pilot study with 50 patients in each group. Included were children of age 5-16 years, referred with already diagnosed renal urolithiasis by X-ray Kidney, Ureter and Bladder (KUB), intravenous pyelogtraphy (IVP) or non contrast computerized tomography (NCCT) of KUB, and fulfilling indications for PCNL. Indications for PCNL were one or more of (1) stone size $\geq 2 \mathrm{~cm}$, (2) partial and complete staghorn stones, (3) stone in lower pole of $>1.0 \mathrm{~cm}$. The children fulfilling the inclusion criteria were recruited prospectively. The first eligible patient was allotted for group 1 (OSD) and next for group 2 (SFD) consecutively until each group had 50 patients.

After explaining the procedure in detail, all of the patients' parents or legal guardians signed a written informed consent form. The procedures of all recruited subjects in the present study were done by two urologists having extensive experience. None was on the learning curve for PCNL or either of the two tract dilation techniques. Subjects with previous renal surgery, uncorrected coagulopathy, ectopic kidney, diverticular stones, chronic kidney disease, malrotated kidneys and skeletal deformity were excluded. Data were recorded and analyzed for demographic variables, location, side, size and composition of the stones along with hemogram, radiation exposure time (total fluoroscopy time in seconds for which c-arm was used (foot on the paddle) from the insertion of a guidewire to the placement of sheath), operative time, rate of stone clearance, duration of hospital stay and complications. Institutional ethical clearance was taken before start of the recruitment of the subjects in the study.

\section{Operative technique}

Under general anesthesia, a 6 Fr ureteric catheter was inserted in lithotomy position. This catheter was used for opacification and distension of the pelvicalyceal system by injecting contrast. After ureteral catheterization, the PCNL was done in prone position. After getting ingress to the pelvicalyceal system through a sheathed needle (two-part trocar needle, M/S Cook Medical), the stylet was removed and a guide wire $(150 \mathrm{~cm}$ Nitinol Terumo hydrophilic guidewire M) was inserted. The tract in both groups was initially dilated by using $8 \mathrm{~F}$ and $10 \mathrm{~F}$ polyurethane dilators and then Alken guide was inserted. Further, tract dilation in group 1 (SFD) was done by using Amplatz dilators (M/S Cook Medical Amplatz Renal Dilators) sequentially with increasing size of dilators by $2 \mathrm{~F}$ each time up to $24 \mathrm{~F}$ and then passing $26 \mathrm{~F}$ sheath or smaller over the last dilator. In group 2 (OSD), further tract dilation was achieved by using Amplatz dilator of 24 F or 26 F size directly without doing it sequentially. Stone fragmentation was done by ultrasonic and ballistic device (M/S Shockpulse-SE, Olympus). Stone fragments were evacuated by using forceps.
Stone clearance confirmation was done by fluoroscopy and rigid (Richard Wolf nephroscope) or flexible (CystoNephroFiberscope, CYF-5, Olympus) nephroscopy in perioperative period while X-ray KUB or NCCT KUB (if the stone was radiolucent) in postoperative period. A $10 \mathrm{~F}$ or $12 \mathrm{~F}$ suction catheter was placed in place of nephrostomy tube in all cases for drainage under gravity. DJ stent of appropriate size according to age (generally age in years +10 is the size of stent) was put when there was intercostal/supracostal puncture, pelvic perforation and impacted upper ureteric stone. Relook PCNL was performed on 3rd postoperative day through the same track or new one for significant residual stone fragments. Patients with considerable intraoperative bleeding and pelvicalyceal system breach had their nephrostomy tube removed on 3rd postoperative day while the rest of the patients got it removed on 2nd postoperative day. A successful outcome was considered if there was no residual stone or fragments $<4 \mathrm{~mm}$ at the end of 3 months post-PCNL irrespective of adjuvant treatments. Modified Clavien-Dindo classification was used for grading the complications. In grade I, requirement of analgesics and antipyretics; in grade II number of blood transfusions, the need for higher antibiotics, and need for treanexamic acid; in grade III DJ stenting, stent repositioning, perinephric abscess, intercostal tube drainage for hydrothorax/pneumothorax, urethral stricture and retention of urine due to blood clot were considered.

\section{Statistical analysis}

The data were collected using a predesigned questionnaire and subsequently were entered in Microsoft Excel. For normally distributed data, proportions were given as percentages, and continuous data were provided as mean \pm SD. An unpaired Student's t-test was used for comparing differences between continuous normally distributed data. The $\mathrm{X}^{2}$ test was used to analyze the proportions. A 95\% confidence interval (CI) was calculated for the differences for means and proportions. A $\mathrm{p}$ value of less than 0.05 was considered significant.

\section{RESULT}

We screened 110 patients with indication of PCNL. We excluded 10 patients with various exclusion criteria, such as previous renal surgery (3), uncorrected coagulopathy (1), ectopic kidney (1), diverticular stones (1), chronic kidney disease (2), malrotated kidneys (1), and skeletal deformity (1). Stone and demographic profiles of the patients were comparable as shown in table 1 . The tract dilation was done successfully in every case. The stone removal was done through the single tract in all cases. The mean operative time, time of radiation exposure, success and failure rate along with hospital stay are given in table 2. Radiation exposure time, mean operative time and drop in hematocrit were statistically less significant in OSD group. Among the additional treatment, PCNL, ESWL and ureteroscopic lithotripsy (URSL) were done 
Table 1 Demographic profile of the patients

\begin{tabular}{|c|c|c|c|c|c|}
\hline \multicolumn{2}{|l|}{ Patients' profile } & Group 1 (SFD) & Group 2 (OSD) & $95 \% \mathrm{Cl}$ & $P$ value \\
\hline \multicolumn{2}{|l|}{ Age (y) } & $10 \pm 3$ & $9.8 \pm 4$ & -1.186 to 1.586 & 0.779 \\
\hline \multicolumn{2}{|l|}{$\operatorname{Sex}(M / F)$} & $29 / 21(58 \% / 42 \%)$ & $28 / 22(56 \% / 44 \%)$ & -0.174 to 0.214 & 0.436 \\
\hline \multicolumn{2}{|c|}{ Stone size in cm (length/width) } & $3.2 \pm 1.1 / 2.2 \pm 0.8$ & $3.7 \pm 1 / 2.5 \pm 0.9$ & -0.912 to $-0.088 /-0.634$ to 0.034 & $0.035 / 0.117$ \\
\hline \multirow[t]{5}{*}{ Stone location } & Pelvic & $16(32 \%)$ & $15(30 \%)$ & & 0.987 \\
\hline & Calyceal & $7(14 \%)$ & 7 (14\%) & & \\
\hline & Pelvic + calyceal & $9(18 \%)$ & $10(20 \%)$ & & \\
\hline & Staghorn & $10(20 \%)$ & $11(22 \%)$ & & \\
\hline & Upper ureteric & $8(16 \%)$ & $7(14 \%)$ & & \\
\hline \multicolumn{2}{|l|}{ Side (right/left) } & $27 / 23$ (54\%/46\%) & $29 / 21(58 \% / 42 \%)$ & -0.234 to 0.154 & 0.585 \\
\hline \multirow[t]{5}{*}{ Stone composition } & Calcium oxalate & $44(88 \%)$ & 45 (90\%) & & 0.993 \\
\hline & Struvite & $1(2 \%)$ & $1(2 \%)$ & & \\
\hline & Apatite & $1(2 \%)$ & $1(2 \%)$ & & \\
\hline & Uric acid & $1(2 \%)$ & $1(2 \%)$ & & \\
\hline & Mixed & $3(6 \%)$ & $2(4 \%)$ & & \\
\hline \multicolumn{2}{|l|}{ Body mass index } & $23.5 \pm 4.8$ & $22.8 \pm 3.9$ & -1.014 to 2.414 & 0.474 \\
\hline \multirow[t]{2}{*}{ Preoperative } & Hemoglobin & $12.5 \pm 1.68$ & $12.9 \pm 1.72$ & -1.066 to 0.266 & 0.293 \\
\hline & Hematocrit & $38.9 \pm 3.89$ & $38.1 \pm 3.52$ & -0.654 to 2.254 & 0.335 \\
\hline \multicolumn{2}{|l|}{ Serum creatinine } & $1 \pm 0.3$ & $1.1 \pm 0.2$ & -0.2 to -0.0 & 0.053 \\
\hline
\end{tabular}

$\mathrm{Cl}$, confidence interval; OSD, one-shot dilation; SFD, sequential fascial dilation.

for the residual stone fragments after the first PCNL. DJ insertion was done in two patients of OSD group (intercostal puncture $=1$, impacted upper ureteric stone $=1$ ) and three patients in SFD group (intercostal puncture $=1$, impacted upper ureteric stone $=1$, pelvic perforation $=1$ ). Relook PCNL was successfully done through old tract with the flexible cystonephroscope. Table 2 shows the complications according to the modified ClavienDindo classification.

\section{DISCUSSION}

Stone incidence is $4.3 \%$ in children. ${ }^{6}$ The strategies for diagnosis, therapy, and follow-up are vastly different from those used in adults. The incidence of stones is increasing in the pediatric patients. This may be due to an increasing sedentary lifestyle, increased fast food consumption, obesity and increased direct and indirect salt intake. ${ }^{7}$

Underlying metabolic and anatomical disorders are the main concerns in children with stone disease. Other concerns in the developing kidney are operative trauma, high recurrence rate, exposure to radiation during procedure and need for retreatment. ${ }^{8}$ Radiation exposure to the surgical team and children is a serious concern. For the first time, Frattini et al reported the oneshot approach as a unique method for PCNL to reduce radiation exposure in adults. ${ }^{9}$

Like other minimally invasive techniques, PCNL is evolving. Renal dilation is one of the most key steps during PCNL. PCNL technique and equipment advancements have improved patient outcomes.5 1011 Many publications have claimed that dilation up to 26 Fr does not result in substantial morbidity in children. Based on renal scarring alone, it has been proven in animal models that employing a small access has no benefit. ${ }^{12}$

There is radiation exposure during PCNL. It is difficult to decrease radiation exposure. To limit radiation exposure, using a single semirigid dilator, often known as 'one-shot', is a good alternative to routine SFD (Amplatz). The findings of this study clearly demonstrated that the OSD is feasible and successful along with reduced radiation exposure. ${ }^{513-18}$ Hosseini et al studied preschool children ( $<6$ years) and showed that fluoroscopy duration was considerably shorter in OSD group. This study also stated that the OSD technique is safe and successful in preschool children. ${ }^{19}$

Rather than using total fluoroscopy time in the present study, we used tract dilation fluoroscopy time because it is a good indicator of the pace of dilation, as the total time is affected by the time spent on the puncture of the pelvicalyceal system, insertion of the guidewire and the search for residual stones after fragmentation and removal.

Bleeding is an important complication, especially in vulnerable populations, such as children. Bleeding can depend on sheath size, stone burden, number of tracts and operative time. Kukreja et al found that the calyx used during intrarenal access had no effect on the development of complications; however, the dilation technique had an effect on bleeding. ${ }^{20}$ In various studies, bleeding requiring transfusion reported between $0.4 \%$ and $24 \% .^{21}{ }^{22}$ In the present study, we found it was $3.0 \%$. This difference could have been attributed to experience 
Table 2 Clinical characteristics and outcome of the patients

\begin{tabular}{|c|c|c|c|c|c|c|}
\hline \multicolumn{3}{|l|}{ Parameters } & Group 1 (SFD) & Group 2 (OSD) & $95 \% \mathrm{Cl}$ & $P$ value \\
\hline \multicolumn{3}{|c|}{ Radiation exposure time (s) } & $47.69 \pm 13$ & $39.12 \pm 15$ & 3.068 to 14.072 & 0.003 \\
\hline \multicolumn{3}{|c|}{ Mean operative time (min) } & $78 \pm 14$ & $70.5 \pm 11$ & 2.565 to 12.435 & 0.004 \\
\hline \multirow{2}{*}{\multicolumn{2}{|c|}{ Perioperative }} & Hemoglobin (g/L) & $110 \pm 15.8$ & $110 \pm 13.1$ & -0.569 to 0.569 & 1 \\
\hline & & Hematocrit & $37.11 \pm 2.45$ & $36.9 \pm 1.97$ & -0.661 to 0.081 & 0.637 \\
\hline \multirow{2}{*}{\multicolumn{2}{|c|}{ Mean drop }} & Hemoglobin & $2.1 \pm 1.08$ & $1.6 \pm 1.4$ & 0.01 to 0.99 & 0.50 \\
\hline & & Hematocrit & $2.1 \pm 1.44$ & $1.44 \pm 1.6$ & 0.063 to 1.257 & 0.032 \\
\hline \multicolumn{3}{|l|}{ Hospital stays (d) } & $4 \pm 1.9$ & $3.2 \pm 1.8$ & 0.075 to 1.525 & 0.80 \\
\hline \multicolumn{3}{|c|}{ Success rate after first PCNL } & $44(88 \%)$ & $45(90 \%)$ & -0.143 to 0.103 & 0.749 \\
\hline \multicolumn{3}{|c|}{ Overall success rate } & $47(94 \%)$ & $46(92 \%)$ & -0.08 to 0.12 & 0.829 \\
\hline \multirow{4}{*}{\multicolumn{2}{|c|}{ Additional treatment }} & PCNL & 2 & 3 & & \\
\hline & & ESWL & 3 & 2 & & \\
\hline & & URSL & 1 & - & & \\
\hline & & DJ stenting & 3 & 2 & & \\
\hline \multirow{10}{*}{$\begin{array}{l}\text { Complications } \\
\text { as per modified } \\
\text { Clavien-Dindo } \\
\text { classification }\end{array}$} & \multirow[t]{3}{*}{ Grade 1} & Fever ${ }^{*}$ & $3(6 \%)$ & $2(4 \%)$ & -0.066 to 0.146 & 0.611 \\
\hline & & $\begin{array}{l}\text { Urine leak after PCN } \\
\text { removal } †\end{array}$ & $2(4 \%)$ & $1(2 \%)$ & & \\
\hline & & Total & $5(10 \%)$ & $3(6 \%)$ & & \\
\hline & \multirow[t]{4}{*}{ Grade 2} & UTI & $3(6 \%)$ & $2(4 \%)$ & -0.077 to 0.157 & 0.648 \\
\hline & & Blood transfusion§ & $2(4 \%)$ & $1(2 \%)$ & & \\
\hline & & $\begin{array}{l}\text { Postoperative } \\
\text { pneumoniaף }\end{array}$ & $1(2 \%)$ & $1(2 \%)$ & & \\
\hline & & Total & $6(12 \%)$ & $4(8 \%)$ & & \\
\hline & \multirow[t]{2}{*}{ Grade 3} & Hydrothorax ${ }^{\star \star}$ & $1(2 \%)$ & $1(2 \%)$ & -0.055 to 0.055 & 1 \\
\hline & & Total & $1(2 \%)$ & $1(2 \%)$ & & \\
\hline & $\begin{array}{l}\text { Total } \\
\text { complicatic }\end{array}$ & & $12(24 \%)$ & $8(16 \%)$ & -7.84 to 23.45 & 0.319 \\
\hline
\end{tabular}

*Managed by antipyretics.

†Managed by compression bandage.

¥Managed by change of antibiotics.

§Managed by blood transfusion.

१Managed by antibiotics.

**Managed by intercostal tube placement.

$\mathrm{Cl}$, confidence interval; ESWL, extracorporeal shock wave lithotripsy; OSD, one-shot dilation; PCN, Percutaneous Nephrostomy; PCNL, percutaneous nephrolithotomy; SFD, sequential fascial dilation; URSL, Ureteroscopic lithotripsy; UTI, Urinary Tract Infection.

of the surgeon, tract dilation method and number of tracts. The frequency of bleeding requiring transfusion was similar between OSD and SFD groups.

Daw et al studied children less than 6 years of age prospectively. They found that Miniperc was comparable with standard PCNL in terms of requirement of blood transfusion. However, operative time was significantly higher, and stone free rate was lower with stone more than two or stone size $\geq 3 \mathrm{~cm}$ in Miniperc group. ${ }^{23}$ These differences may have been attributed to smaller size of tract, reduced intraoperative field visibility and the requirement of more time to break into smaller fragments and extract. Meta-analyses showed comparable results between MiniPCNL versus standard PCNL regarding fever, urinary tract perforation, leakage and needing blood transfusion. ${ }^{24} 25$ Similar findings have also been reported by other researchers. ${ }^{9} 10131516$ Presently, PCNL is being performed through smaller tract size, such as Miniperc/MiniPCNL (11-20 Fr) and Microperc/MicroPCNL (4.8 Fr) to reduce blood loss and other complications. Our results showed that the OSD did not cause more complications, including bleeding, than SFD. Telescopic, balloon, and OSD had similar hematologic safety profiles in a clinical research by Frattini $e t$ al. Similarly, telescopic and OSD had similar complication rates in a randomized study by Falahatkar et al. ${ }^{9} 1019$ 26-28

The strength of the present pilot study is the sufficient number of patients in both comparable groups for confounding factors. The limitation of the present study is that there was no long-term follow-up for renal scarring after the PCNL. It would have been better if the present study was done as a randomized controlled trial. 
In conclusion, the OSD is feasible, safe and well tolerated in the pediatric age group. In addition to comparable complications, this method also provides reduced radiation exposure for children as well as operating surgeons and nursing teams along with shorter operative time.

\section{Acknowledgements The authors thank the staff of the Department of Urology.}

Contributors All of the authors have read and approved the manuscript. Specific authors' contributions are as follows: AS contributed to methodology, data curation, validation and writing the original draft. KKY contributed to methodology, data curation, formal analysis, validation, writing the original draft, and review and editing. AS contributed to methodology, data curation, validation, and writing the original draft. AKS contributed to data curation, validation, and writing the original draft. SKS contributed to conceptualization, methodology, data curation, supervision, validation, writing the original draft, and review and editing. SKS is responsible for the overall content as the guarantor.

Funding The authors have not declared a specific grant for this research from any funding agency in the public, commercial or not-for-profit sectors.

Competing interests None declared.

Patient consent for publication Not required.

Ethics approval The study was approved by the Ethical Review Committee of $\mathrm{Dr}$ RML Institute of Medical Sciences, Lucknow, Uttar Pradesh, India.

Provenance and peer review Not commissioned; externally peer reviewed.

Data availability statement Data are available upon reasonable request.

Open access This is an open access article distributed in accordance with the Creative Commons Attribution Non Commercial (CC BY-NC 4.0) license, which permits others to distribute, remix, adapt, build upon this work non-commercially, and license their derivative works on different terms, provided the original work is properly cited, appropriate credit is given, any changes made indicated, and the use is non-commercial. See: http://creativecommons.org/licenses/by-nc/4.0/.

\section{REFERENCES}

1 Lingeman JE, Newman D, Mertz JH, et al. Extracorporeal shock wave lithotripsy: the Methodist hospital of Indiana experience. J Urol 1986;135:1134-7.

2 Lam HS, Lingeman JE, Barron M, et al. Staghorn calculi: analysis of treatment results between initial percutaneous nephrostolithotomy and extracorporeal shock wave lithotripsy monotherapy with reference to surface area. J Urol 1992;147:1219-25.

3 Woodside JR, Stevens GF, Stark GL, et al. Percutaneous stone removal in children. $J$ Urol 1985;134:1166-7.

4 DeMarco RT. Percutaneous nephrolithotomy in children. Adv Urol 2011:2011:1-6.

5 Ozok HU, Sagnak L, Senturk AB, et al. A comparison of metal telescopic dilators and Amplatz dilators for nephrostomy tract dilation in percutaneous nephrolithotomy. $J$ Endourol 2012;26:630-4.

6 Erdenetsesteg G, Manohar T, Singh H, et al. Endourologic management of pediatric urolithiasis: proposed clinical guidelines. $J$ Endourol 2006;20:737-48.

7 Guan N, Fan Q, Ding J, et al. Melamine-contaminated powdered formula and urolithiasis in young children. $N$ Engl $J$ Med 2009;360:1067-74.
8 Muslumanoglu AY, Binbay M, Yuruk E, et al. Updated epidemiologic study of urolithiasis in Turkey. I: changing characteristics of urolithiasis. Urol Res 2011;39:309-14.

9 Frattini A, Barbieri A, Salsi P, et al. One shot: a novel method to dilate the nephrostomy access for percutaneous lithotripsy. $J$ Endourol 2001;15:919-23.

10 Falahatkar S, Neiroomand $\mathrm{H}$, Akbarpour $\mathrm{M}$, et al. One-Shot versus metal telescopic dilation technique for tract creation in percutaneous nephrolithotomy: comparison of safety and efficacy. J Endourol 2009;23:615-8

11 Baldwin DD, Maynes LJ, Desai PJ, et al. A novel single step percutaneous access sheath: the initial human experience. J Urol 2006;175:156-61.

12 Traxer O, Smith TG, Pearle MS, et al. Renal parenchymal injury after standard and mini percutaneous nephrostolithotomy. J Urol 2001;165:1693-5.

13 Li Y, Yang L, Xu P, et al. One-Shot versus gradual dilation technique for tract creation in percutaneous nephrolithotomy: a systematic review and meta-analysis. Urolithiasis 2013;41:443-8.

14 Dehong C, Liangren L, Huawei L, et al. A comparison among four tract dilation methods of percutaneous nephrolithotomy: a systematic review and meta-analysis. Urolithiasis 2013;41:523-30.

15 Srivastava A, Singh S, Dhayal IR, et al. A prospective randomized study comparing the four tract dilation methods of percutaneous nephrolithotomy. World J Urol 2017;35:803-7.

16 Amirhassani S, Mousavi-Bahar SH, Iloon Kashkouli A, et al. Comparison of the safety and efficacy of One-shot and telescopic metal dilatation in percutaneous nephrolithotomy: a randomized controlled trial. Urolithiasis 2014;42:269-73.

17 Suelozgen T, Isoglu CS, Turk H, et al. Can we use single-step dilation as a safe alternative dilation method in percutaneous nephrolithotomy? Urology 2017;99:38-41.

18 Ucar M, Kisa E, Celik F. Can single step dilation technique in pediatric percutaneous nephrolithotomy be an effective alternative to stepwise dilation? J Surg Med 2019;3:583-7.

19 Hosseini SR, Mohseni MG, Alizadeh F. One shot tract dilation for percutaneous nephrolithotomy: is it safe and effective in preschool children? Urol Int 2014;92:440-3.

20 Kukreja R, Desai M, Patel S, et al. Factors affecting blood loss during percutaneous nephrolithotomy: prospective study. J Endourol 2004;18:715-22.

21 Bogris S, Papatsoris AG. Status quo of percutaneous nephrolithotomy in children. Urol Res 2010;38:1-5.

22 Zeng G, Zhao Z, Wan S, et al. Comparison of children versus adults undergoing mini-percutaneous nephrolithotomy: large-scale analysis of a single institution. PLoS One 2013;8:e66850.

23 Daw K, Shouman AM, Elsheemy MS, et al. Outcome of Minipercutaneous nephrolithotomy for renal stones in infants and preschool children: a prospective study. Urology 2015;86:1019-26.

24 Jiao B, Luo Z, Huang T, et al. A systematic review and meta-analysis of minimally invasive vs. standard percutaneous nephrolithotomy in the surgical management of renal stones. Exp Ther Med 2021;21:213.

25 Mahmood SN, Aziz BO, Tawfeeq HM, et al. Mini- versus standard percutaneous nephrolithotomy for treatment of pediatric renal stones: is smaller enough? J Pediatr Urol 2019;15:664.e1-664.e6.

26 Peng P-X, Lai S-C, Ding Z-S, et al. One-Shot dilation versus serial dilation technique for access in percutaneous nephrolithotomy: a systematic review and meta-analysis. BMJ Open 2019;9:e025871.

27 Desai MR, Kukreja RA, Patel SH, et al. Percutaneous nephrolithotomy for complex pediatric renal calculus disease. $J$ Endourol 2004;18:23-7.

28 Kapoor R, Solanki F, Singhania P, et al. Safety and efficacy of percutaneous nephrolithotomy in the pediatric population. $J$ Endourol 2008;22:637-40. 